DOI: 10.12731/2658-4034-2019-2-64-73

УДК 159.9.075

\title{
СОЦИАЛЬНО-ПСИХОЛОГИЧЕСКИЕ ПРОБЛЕМЫ СОЦИАЛИЗАЦИИ СТУДЕНТОВ С ОГРАНИЧЕННЫМИ ВОЗМОЖНОСТЯМИ ЗДОРОВЬЯ В ОБРАЗОВАТЕЛЬНУЮ СРЕДУ ВУЗА
}

Барсуков А.В., Шуткина Ж.А., Бурова Е.А.

Цель. Статья посвящена актуальной в современном обществе теме социализации студентов с ограниченными возможностями здоровья в образовательную среду ВУЗа. Сочиильная среда, и в частности среда ВУЗа, не всегда толерантна к лицам с ограниченными возможностями. Гандикаппизм, патеррналисткое и интоллерантное отношение усложняют социальное взаимодействие студентов с ограниченными возможностями и нормально развивающимися сверстниками. В статье рассматриваются психологические факторы, препятствующие оптимальной адаптации студентов с ограниченными возможностями здоровья в среду ВУЗа. Акиент делается на личностных качествах, осложняющих сочиальное взаимодействие студентов с ограниченными возможностями.

Результаты. Результаты работы заключаются в том, что авторы приводят данные, свидетельствующие о том, что подготовка педагогов ВУЗа, студентов так же необходима, как и подготовка самих студентов с ограниченными возможностями. Рассматривается опыт ВУЗов по решению проблем адаптации студентов с ограниченными возможностями здоровья. Для информационной поддержки преподавателей об особенностях детей с ОВЗ созданы специальные учебно-методические комплексы. Для студентов с ОВЗ реализуются различные тренинговые программы, предусмотрены методические материаль в виде памяток, внедрен алгоритм психолого-педагогчческой поддержки от этапа поступления и адаптащии к вузу до трудоустройства. 
Область применения результатов. Результаты исследования могут быть применены в сочиильной сфере, связанной с сочиализацией студентов с ограниченными возможностями здоровья в образовательную среду ВУЗа.

Ключевые слова: студенты с ограниченныли возможностями; виктимность; гандикаппизм; коммуникативные установки; личностные гранищь;; инклюзия.

\section{SOCIAL AND PSYCHOLOGICAL PROBLEMS OF SOCIALIZATION OF STUDENTS WITH LIMITED OPPORTUNITIES OF HEALTH ON EDUCATIONAL ENVIRONMENT OF HIGHER EDUCATION INSTITUTION}

\section{Barsukov A.V., Shutkina Zh.A., Burova E.A.}

Purpose. The article is devoted to the topic of socialization of students with disabilities relevant in social environment of the university. The social environment, and in particular the environment of the university, it's not always tolerant of persons with disabilities. Handicapism, Paternalistic and intollerant attitudes complicate the social interaction of students with disabilities and normally developing peers. The article discusses the psychological factors that impede the optimal adaptation of students with disabilities in the university environment. The emphasis is on personal qualities that complicate the social interaction of students with disabilities.

Results. The authors'data indicate that the preparation of teachers of the university, students is as necessary as also the preparation of students with disabilities. The experience of universities in solving the problems of adaptation of students with disabilities are considered. For informational support of teachers about the features of children with disabilities, special educational and methodical complexes have been created. For students with disabilities, various training programs are implemented, methodological materials in the form of leaflets are provided, an algorithm of psychological and pedagogical support is introduced from the stage of admission and adaptation to the university of enrollment. 
Practical implications. The results of the study can be applied in the social sphere with the socialization of students with disabilities in the educational environment of the university.

Keywords: students with disabilities; victimization; handicappism; communicative attitudes; personal boundaries; inclusion.

\section{Введение}

Проблема личности инвалидов и их интеграции в образовательную среду (инклюзия), и шире - в социальную среду, по сей день остается крайне дискуссионной. Проблемным является вопрос формирования личности инвалида и специфики отношения к дефекту, прежде всего семьи, а также более широкого круга лиц, определяющих социализацию и онтогенез личности с тем или иным дефектом. Р. Бернс утверждал, реакция на собственный дефект это отражение реакций окружающих. Первично ребенок с ограниченными возможностями здоровья (далее ОВ3) воспринимает реакции родителей, затем педагогов и сверстников. К периоду поступления в ВУЗ у них формируется особый склад личности, отличный от нормально развивающихся сверстников. В контексте данной статьи приведем некоторые эмпирические и теоретические данные, касающиеся личностных особенностей студентов с ОВ3.

\section{Результаты и обсуждение}

Е.С. Фоминых исследовала фактор виктимного поведения и коммуникативных особенностей студентов инвалидов. Коммуникативные установки студентов инвалидов определяют качество и специфику адаптации в социальной среде ВУЗа. Виктимность взаимосвязана с коммуникативными установками и трактуется как склонность жертвы преступления, насилия подсознательно провоцировать преступника. В исследованиях Е.С. Фоминых выявлено, что $62 \%$ студентов инвалидов демонстрируют готовность к виктимному поведению (либо в следствии дифицитарности планирования социального поведения, либо в следствии несформированности адаптивных моделей коммуникативного поведения). У $64 \%$ студентов инвалидов 
снижены показатели гиперсоциального поведения, что говорит о социальной пассивности, низком социальном интересе. У испытуемых отмечается чувство изолированности от социальных процессов. 66,7\% испытуемых обнаруживают склонность к пассивному варианту виктимного поведения, для них характерна установка на беспомощность, убежденность в неспособности к самостоятельному разрешению ситуации. 44\% некритичны в ситуациях общения со сверстниками и педагогами. Из приведенных данных авторы делают вывод, что специфика их личности определяет один из механизмов виктимной активности [5].

Актуальной позицией студентов-инвалидов является позиция Я-ребенок, зависимость от окружающих, склонность к некритичному поведению, а также аутодиструктивным формам поведения, это может свидетельствовать о том, что студенты - инвалиды нуждаются в девиктимизации, коррекции коммуникативных установок.

Личностные границы есть базис суверенности, основа формирования субъектности (К.А. Альбуханова-Славская). При излишни проницаемых границах субъект становится более уязвим для влияния и воздействия из вне. Личностные границы определяют не только суверенность физического пространства, но и личных вещей, вкусов, социальных связей, ценностей (С.К. Нартова-Бочавер). По данным Е.С. Фоминых депривированную суверенность имеют $67 \%$ студентов инвалидов. У 54\% депривированна суверенность территории, что способствует виктимизации личности в студенческой среде. Обобщая теоретические данные можно сделать вывод, что студенты с ограниченными возможностями обладают повышенным виктимным потенциалом, обладают личностными особенностями, затрудняющими их безболезненное включение в коллектив сверстников [6].

Заслуживают внимания социально-психологические факторы (имеются в виду факторы среды ВУЗа), осложняющие адаптацию студентов-инвалидов к социальной среде ВУЗа.

О.А. Ставицкий акцентирует внимание на проблеме социализации инвалидов в среде ВУЗа в связи с негативными представлениями о людях с ограниченными возможностями. В некоторых источниках 
негативные установки, представления и отношения окружающих к инвалидам называются гандикапизмом. Данные взгляды содержатся в общественном сознании, выявляются на неосознанном уровне (коллективное бессознательное, архетипы). Согласно факторной модели О.А. Ставицкого доминирующими факторами гандикапизма являются страх, тревога, психологический дискомфорт при общении с инвалидами. В связи с наличием страха и тревоги предлагается термин гадифобность, как отдельная неклиническая категория схожая с ксенофобией.

Гандифобность - предполагает чувство страха при общении с инвалидами, или просто при их виде, что порождает желание дистанцироваться от них [3].

Данный феномен формируется отчасти по механизму «свойчужой». Человек подсознательно относит инвалида к категории «чужой», в связи с различиями. По мнению О.А. Ставицкого, общение с инвалидом провоцирует чувство страха приобретения инвалидизирующего заболевания. В данном процессе участвуют механизмы эмпатии и идентификации [3]. То есть страх обусловлен не отвержением инвалида, а желанием освободить себя от негативных мыслей, эмоций, подсознательно человек боится сам приобрести увечья при виде инвалида с соматическим дефектом. Страх также обусловлен незнанием специфики общения с инвалидом.

Во-первых, инвалиду может стать плохо, во - вторых, инвалидность накладывает отпечаток на восприятия себя и мира, влияет на развитие личности. Возникает ощущение что общаться с такими людьми надо по- особому, что некоторые фразы могут обидеть больного. Присутствует также страх, который метафорически можно назвать страх «заражения». Подсознательные механизмы гандифобности, вероятно базируются на страхе смерти. В данном случае одним из наиболее доступных и экономичных методов предотвращения, профилактики «боязни» лиц с ограниченными возможностями является просвещение, информирование и т д.

Таким образом, интеграция студентов с ОВЗ в среду ВУЗа является не только организационной проблемой, но системной психологиче- 
ской. У.В. Ульянкова отмечала, что нельзя в вопросах инклюзивного образования ограничиваться организационными вопросами в ущерб психологическим [4]. Например, обеспечить родителей и педагогов необходимой консультативной помощью, сделать более комфортной для детей с ограниченными возможностями образовательную среду. Проблемным так же является вопрос повышения психологической готовности ребенка с ограниченными возможностями к совместному с нормально развивающимися сверстниками обучению.

Студенты с ограниченными возможностями, на наш взгляд, нуждаются в специальной психологической подготовке при интеграции в общеобразовательную среду ВУЗа. Им необходимо психологическое сопровождение в течение всего периода обучения. При этом под сопровождением следует понимать не только психолого-педагогические мероприятия, но также социально-психологические и консультативные. Такие особенности студентов с ограниченными возможностями как высокий виктимный потенциал, специфика личностных, коммуникативных качеств, наличие в ряде случаев физических дефектов определяет сложности их взаимодействия в студенческой среде.

Социальная среда, и в частности среда ВУЗа, не всегда толерантна к лицам с ограниченными возможностями. Гандикаппизм, патеррналисткое и интоллерантное отношение усложняют социальное взаимодействие студентов с ограниченными возможностями и нормально развивающимися сверстниками. Приведенные данные свидетельствуют о том, что подготовка педагогов ВУЗа, студентов так же необходима, как и подготовка самих студентов с ограниченными возможностями.

Ю.В. Мельник, С.В. Панюкова, Г.Г. Сайтгалиева, О.А. Серебренникова обобщают опыт российских ВУЗов по интеграции студентов с ОВ3 в российских вузах. Основной акцент в их работе делается все же на организационных вопросах. Тем не менее отмечается, что в ряде ВУЗов созданы условия для психолого-педагогического сопровождения детей с ОВ3, а также психологическая работа с родителями и опекунами, а также педагогами [2]. 
О.А. Денисова и О.Л. Леханова описывают региональный опыт обучения студентов с ОВ3 в Череповецком государственном университете, где был создан ресурсный центр поддержки детей с OB3, занимающийся психолого-педагогической, консультативной, коррекционно-психологической и дефектологической помощью детям с ОВ3 [1].

\section{Заключение}

Для информационной поддержки преподавателей об особенностях детей с ОВ3 были созданы специальные учебно-методические комплексы. Обучение педагогов способствует снижению страха перед инвалидами. Если бессознательные или установочные явления гандифобности поддаются лишь частичной коррекции, а в среде ВУЗа на это просто не хватит ресурсов, то информирование снимет поверхностное волнение, повысит готовность педагогов к полноценной работе с студентами с ОВ3. Что касается студентов с ОВ3, то для них так же предусмотрены методические материалы в виде памяток. Для всех студентов реализуются различные тренинговые программы (мы полагаем, для обучения совместному взаимодействию нормально развивающихся студентов и студентов с ОВ3, так как авторы не уточняют) [1]. Внедрен алгоритм психолого-педагогической поддержки от этапа поступления и адаптации к вузу до трудоустройства. Данные меры не являются избыточными, а скорее минимально необходимыми для успешного включения детей с OB3 в общеобразовательный процесс.

\section{Информация о конфликте интересов.}

Авторы заявляют об отсутствии конфликта интересов.

\section{Список литературы}

1. Денисова О.А., Леханова О.Л. Инклюзивное образование студентов с инвалидностью в региональном многопрофильном ВУЗе на примере Череповецкого государственного университиет а// Психологическая наука и образование. 2017. Т. 22. № 1. С. 119-129. 
2. Мельник Ю.В., Панюкова С.Р., Сайтгалиева Г.Г. Отечественный и зарубежный опыт ВУЗов по обучению и сопровождению студентов с инвалидностью // Психологическая наука и образование. 2017. Т. 22. № 1. С. 88-97.

3. Ставицкий О.А. Психологическая модель гандифобности // Перспективы науки и образования. 2014. № 1. С. 212-215.

4. Ульянкова У.В., Дмитриева Е.Е. Проблема интеграции детей с умеренными отклонениями в развитии в общеобразовательную среду // Проблемный ребенок в современном социокультурном пространстве образования и семьи: материалы международной научно-практической конференции. Н.Новгород: НГПУ, 2009. С. 10-18.

5. Фоминых Е.С. Коммуникативные установки студентов инвалидов как условие виктимности // Вестник ЧГПУ. № 9. 2011. С. 200-207.

6. Фоминых Е.С. Нарушение личностных границ студента инвалида в контексте его виктимной деформации // Известия ВГПУ: психологические проблемы современного образования. 2012. № 1. С. 122-125.

\section{References}

1. Denisova O.A., Lekhanova O.L. Inklyuzivnoye obrazovaniye studentov $\mathrm{s}$ invalidnostyu $\mathrm{v}$ regionalnom mnogoprofilnom VUZe na primere Cherepovetskogo gosudarstvennogo universitiyeta [Inclusive education of students with disabilities in a regional diversified university based on the example of Cherepovets State University]. Psikhologicheskaya nauka i obrazovaniye [Psychological Science and Education], 2017, no. 1, pp. 119-129.

2. Mel'nik YU.V., Panyukova S.R., Sajtgalieva G.G. Otechestvennyj i zarubezhnyj opyt VUZov po obucheniyu i soprovozhdeniyu studentov s invalidnost'yu [Domestic and foreign experience of universities in teaching and accompanying students with disabilities]. Psikhologicheskaya nauka i obrazovanie [Psychological Science and Education], 2017, no. 1, pp. 88-97.

3. Stavitskij O.A. Psikhologicheskaya model' gandifobnosti [Psychological model of handiwayness]. Perspektivy nauki i obrazovaniya [Perspectives of science and education]. 2014, no. 1, pp. 212-215. 
4. Ul'jankova U.V., Dmitrieva E.E. Problema integracii detej s umerennymi otklonenijami v razvitii v obshheobrazovatel'nuju sredu [The problem of integration of children with moderate developmental disabilities into the general educational environment]. The paper presented in the conference proceedings «Problemnyj rebenok $v$ sovremennom sociokul 'turnom prostranstve obrazovanija $i$ sem ' $i$ » [Problem child in the modern socio-cultural space of education and family]. N.Novgorod: NGPU, 2009, pp. 10-18.

5. Fominyh E.S. Kommunikativnye ustanovki studentov invalidov kak uslovie viktimnosti [Communicative attitudes of students with disabilities as a condition of victimization]. Vestnik ChGPU [Vestnik ChGPU]. 2011, no. 9, pp. 200-207.

6. Fominyh E.S. Narushenie lichnostnyh granic studenta invalida v kontekste ego viktimnoj deformacii [Violation of the personal boundaries of a student with a disability in the context of his victimization strain]. Izvestija VGPU: psihologicheskie problemy sovremennogo obrazovanija [Izvestiya VSPU: psychological problems of modern education]. 2012. no. 1, pp. 122-125.

\section{ДАННЫЕ ОБ АВТОРАХ}

Барсуков Александр Валерьевич, доцент кафедры общей и социальной психологии, доцент, кандидат психологических наук Федеральное государственное автономное образовательное учреждение высшего образования «Начиональный исследовательский Нижегородский государственный университет им. Н.И. Лобачевского»

пер. Университетский, 7, г. Нижний Новгород, 603000, Российская Федерачия alexbars80@rambler.ru.

Шуткина Жанна Александровна, доцент кафедры общей и социальной психологии, доцент, кандидат педагогических наук Федеральное государственное автономное образовательное учреждение выстего образования «Начиональный исследовательский Нижегородский государственный университет им. Н.И. Лобачевского» 
пер. Университетский, 7, г. Нижний Новгород, 603000, Российская Федерация

zhannashutkina@mail.ru

Бурова Екатерина Алексеевна, психолог кафедры общей и социальной психологии

Федеральное государственное автономное образовательное учреждение высшего образования «Национальный исследовательский Нижегородский государственный университет им. Н.И. Лобачевского»

пер. Университетский, 7, г. Нижний Новгород, 603000, Российская Федеращия

ekaterinaburova1@mail.ru

\section{DATA ABOUT THE AUTHORS}

Barsukov Aleksandr Valerievich, Associate Professor, Department of General and Social Psychology, Ph.D. in psychology, Associate Professor

Lobachevsky State University of Nizhni Novgorod

7, per.Universitetskii, Nizhnij Novgorod, 603000, Russian Federation alexbars80@rambler.ru

Shutkina Zhanna Aleksandrovna, Associate Professor, Department of General and Social Psychology, Ph.D. in pedagogy, Associate Professor

Lobachevsky State University of Nizhni Novgorod

7, per.Universitetskii, Nizhnij Novgorod, 603000, Russian Federation zhannashutkina@mail.ru

Burova Ekaterina Alekseevna, psychologist, Department of General and Social Psychology, Ph.D. Student Lobachevsky State University of Nizhni Novgorod 7, per.Universitetskii, Nizhnij Novgorod, 603000, Russian Federation ekaterinaburova1@mail.ru 